\title{
An Insight on Thermophysical Properties of Binary Mixtures of Hydrocarbons with Spectroscopic Evidence; Essential Components of Transformer Oils
}

\author{
Sanghamitra Pradhan ${ }^{1}$ (D), Manaswini Chhotaray ${ }^{2}{ }^{(\mathbb{D})}$,Sujata Mishra $3 *$ (D)
}

1 Department of Chemistry, Institute of Technical Education and Research, Siksha'O'Anusandhan, Deemed to be University, Khandagiri Square, Bhubaneswar, 751030, Odisha, India; Sanghamitra.pradhan85@gmail.com;

2 Department of Chemistry, Institute of Technical Education and Research, Siksha'O'Anusandhan, Deemed to be University, Khandagiri Square, Bhubaneswar, 751030, Odisha, India; Manaswinichhotaray96@gmail.com

3 Department of Chemistry, Institute of Technical Education and Research, Siksha'O'Anusandhan, Deemed to be University, Khandagiri Square, Bhubaneswar, 751030, Odisha, India; drsujatamishra97@gmail.com

* Correspondence: drsujatamishra97@gmail.com; Scopus ID: 7203777707

Abstract: The aim of the present investigation is to analyze the effect of carbon chain length in benzene +

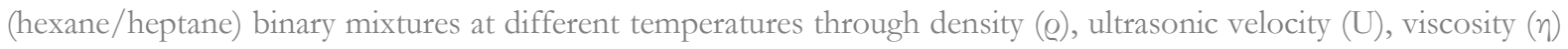
and dielectric ( $(\varepsilon)$ measurements. Derived properties such as molar volume $(V)$, isentropic compressibility $\left(\beta_{s}\right)$, acoustic impedance $(Z)$ and intermolecular free length $\left(L_{f}\right)$ have been calculated for $T=298.15,308.15$ and $318.15 \mathrm{~K}$. The excess values of the above mentioned properties of the binary mixtures of benzene + (hexane/heptane) are determined at different temperatures and have been fitted to Redlich - Kister polynomial equation. The dielectric permittivity results demonstrate that deviations from pure components are mostly negative in both the mixtures except for few cases in benzene rich region. Excess Gibb's free energy of activation of viscous flow $\left(G^{\mathrm{E}}\right)$ has been calculated using the viscosity measurements at different temperatures. Mixing rules have been adopted to calculate the ultrasonic velocities of the binary mixtures of benzene + (hexane/heptane) at the above said temperatures. FT-IR and NMR analysis have been done to check the accuracy of the results.

Keywords: Temperature; Ultrasonic velocity; Dielectric permittivity; Excess properties and Binary mixture.

(C) 2020 by the authors. This article is an open access article distributed under the terms and conditions of the Creative Commons Attribution (CC BY) license (http://creativecommons.org/licenses/by/4.0/).

\section{Introduction}

The studies of physicochemical activities and molecular interactions have gained much importance during the last two decades. A number of experimental procedures have been utilised to

examine the associations between the components of binary liquid mixture [1]. An analysis of literature specifies that excess values of ultrasonic velocity, adiabatic compressibility and molar volume in liquid 


\section{Sanghamitra Pradhan, Manaswini Chhotaray, Sujata Mishra}

mixtures serve as vital tools in elucidating the molecular association between the solute and solvent molecules and they find uses in several industrial and technological practices [2].Elucidation of ion-solvent, ion-ion interactions in mixed solvents can be done by density and ultrasonic measurements. Ultrasonic measurements serve as a good tool to assess the molecular interactions in binary and ternary liquid mixtures [3].Ultrasonic speed measurement and derived parameters provide qualitative information in characterising the physical aswell as chemical behaviour of liquid mixtures. It depends upon the structure of the components andtheir interactions in the binary mixture which is related to the binding forces between the components and is also sensitive to temperature. Acoustic parameters which can be estimated with the help of speed of sound are sensitive to composition of the mixture i.e. molecular arrangement in the solution which takes place as a result of intermolecular interaction [4]. The structural properties of the binary mixtures can be well judged by the dielectric constant that comprises both the enduring dipole moments of the molecules and polarizability. Dielectric constant refers to the distortion of molecules and gets enhanced with both dipole moment and polarizability [5]. Induced dipole-induced dipole interactions which arise due to polarizability aspects take place in binary mixtures containing non - polar components. Such type of interaction between nonpolar molecules originates from the transient or temporary dipoles which arise due to variations in the immediate distribution or position of the electrons. The force of attraction is very weak in case of induced dipole-induced dipole interactions so optical methods cannot be used to detect and access these interactions.

Literature survey shows that few studies have been carried out based on induced dipole -induced dipole interactions in the binary mixtures. Measurement of density and excess studies on volume has already been performed for binary mixture of benzene and hexane [6]. Different physicochemical properties of binary liquid

\section{Materials and Methods}

The chemicals benzene, hexane and heptane used in this study are of analytical status and purchased from Merck Chemicals Ltd. India and have pureness $>99 \%$. The purity of the chemicals has been checked by comparing measured values of mixtures of aliphatic hydrocarbons with benzene have been studied with benzene at $298.15 \mathrm{~K}$ and atmospheric pressure [7]. The velocities of sound and density for binary mixtures of benzene, hexane and methanol with respect to temperature have been recorded. On the basis of solution theory, there is a probability of attraction between the $\pi$ electrons of the benzene ring and hexane [8]. But with rise in temperature, there is no deviance since the distribution of hexane molecules get affected by the benzene rings which are planar.

Aromatic hydrocarbons serve as important raw materials for the production of petrochemicals in the industries. With the aid of liquid -liquid extraction, vital aromatic compounds having commercial importance are extracted from refinery products [9]. The mixture of aromatic and aliphatic hydrocarbons is used as electric transformer oils [10]. The physico-chemical behaviour of these compounds plays a decisive role in anticipating their performance characteristics. The capacity of oil to tune to various stresses depends mostly on these physico-chemical properties such as density, viscosity, permittivity, etc.

The studies in the literature regarding nonpolar-nonpolar interactions in liquid mixtures are very few and usually focus on density, molar volume and ultrasonic speed mostly at $298.15 \mathrm{~K}$. Therefore, an update systematic investigation of excess thermophysical properties that yield vital information about the intermolecular associations of the binarymixtures at different temperatures is required. Since further investigations are required to elucidate the interactions existing in binary mixtures, an attempt has been made to study thoroughly the physicochemical behaviour of benzene with homologous series of aliphatic hydrocarbons such as hexane/heptane at three different temperatures $(298.15 \mathrm{~K}, 308.15 \mathrm{~K}$ and $318.15 \mathrm{~K})$. This manuscriptprovides a complete scrutiny of different thermophysical properties at different temperatures using techniques which are more accurate than already published accompanied by spectroscopic evidence.

density, dielectric and ultrasonic speeds with those reported in literature, represented in Table 1. Standard error in the order of $10^{-3}$ has been noticed for the deviations of experimental values with the 


\section{An Insight on Thermophysical Properties of Binary Mixtures of Hydrocarbons with Spectroscopic Evidence; Essential Components of Transformer Oils}

literature values. To avoid volume loss all the chemicals are stored in proper air tight containers.

Binary mixture solutions were prepared on the basis of mole fraction bydissolving benzene in appropriate amount of hexane/heptane. Density $\left(\mathrm{kgm}^{-3}\right)$, ultrasonic velocity $(\mathrm{m} / \mathrm{s})$ and viscosity (mPas) of the binary mixtures at $\mathrm{T}=298.15 \mathrm{~K}$, $308.15 \mathrm{~K}$ and $318.15 \mathrm{~K}$ are recorded using automatic density and ultrasonic velocity meter (DSA 5000 M, Anton Paar). The operating frequency of the instrument is $2 \mathrm{MHz}$ having accuracy of \pm 0.00005 $\mathrm{kgm}^{-3}$ for density and $\pm 0.5 \mathrm{~m} / \mathrm{s}$ for ultrasonic velocity. $\pm 0.5 \%$ uncertainty has been noticed for viscosity measurements using the viscometer. With the help of built in thermostat, the temperature has been controlled up to $\pm 0.01 \mathrm{~K}$. In order to make the measurements error free, proper care has been taken while inserting the sample into the apparatus using the syringe to avoid the formation of bubbles. Dipole meter ((Mittal Enterprises, New Delhi) has been used to carry out dielectric measurements and with the help of digital temperature water bath water has been circulated through the double walled measuring cell. A stable wave frequency of $500 \mathrm{KHz}$ has been maintained with an audio oscillator. The uncertainty in the values of dielectric permittivity is within accuracy of \pm 0.005 and the instrument has been calibrated with the help of reference liquid. NMR spectra have been collected using Jeol 400 $\mathrm{MHz}$ NMR spectrometer. FT-IR analysis has been performed using Perkin Elmer spectrum two with UTAR spectrometer.

Table 1. List of experimental and literature values of density, ultrasonic velocity and dielectric permittivity of benzene, hexane and heptane at different temperatures.

\begin{tabular}{c|c|c|c|c|c}
\hline Components & \multirow{2}{*}{$\mathrm{T}(\mathrm{K})$} & \multicolumn{2}{c|}{$\varrho\left(\mathrm{kgm}^{-3}\right)$} & \multicolumn{2}{c}{$\mathrm{U}(\mathrm{m} / \mathrm{s})$} \\
\cline { 3 - 6 } & & Expt & Lit. & Expt & Lit. \\
\cline { 3 - 6 } & & & & & \\
\hline \multirow{5}{*}{ Benzene } & 298.15 & 873.48 & $873.61[11]$ & 1298.53 & $1299.3[13]$ \\
\cline { 2 - 6 } & 308.15 & 862.75 & $862.90[11]$ & 1251.90 & $1252.8[13]$ \\
\cline { 2 - 6 } & 318.15 & 851.95 & $852.2311]$ & 1206.25 & $1207.2[13]$ \\
\hline \multirow{3}{*}{ Hexane } & 298.15 & 667.44 & $660.20[11]$ & 1081.29 & $1076.3[12]$ \\
\cline { 2 - 6 } & 308.15 & 657.90 & $655.20[12]$ & 1035.90 & $1032.4[12]$ \\
\cline { 2 - 6 } & 318.15 & 648.46 & $646.60[12]$ & 990.84 & \\
\hline \multirow{5}{*}{ Heptane } & 298.15 & 679.12 & $679.55[12]$ & 1080.85 & $1108.0[14]$ \\
\cline { 2 - 6 } & 308.15 & 671.94 & $671.00[12]$ & 1035.72 & $1042.0[14]$ \\
\cline { 2 - 6 } & 318.15 & 658.51 & & 990.84 & \\
\hline
\end{tabular}

Values of thermo acoustic properties such as $\beta_{s}, Z$ and $L_{f}$ have been calculated using ultrasonic velocity $(u)$.

$$
\begin{aligned}
& \beta s=\frac{1}{\rho u^{2}} \\
& Z=\rho u \\
& L_{f}=\mathrm{K} \beta_{s}^{1 / 2}
\end{aligned}
$$

where $\quad K$ is the Jacobson's temperature dependent constant and $\mathrm{T}$ is the experimental temperature in absolute scale [15].

From the density results, excess molar volumes $\left(V^{\mathrm{E}}\right)$ have been calculated for binary mixtures of benzene + hexane/heptane.

$$
V^{E}=V-\left(V_{1} X_{1}+V_{2} X_{2}\right)
$$

where $V$ is the molar volume of the binary mixture; $V_{1}, V_{2}, X_{1}$ and $X_{2}$ are the molar volumes and mole fractions of solvent (hexane/heptane) and solute (benzene), respectively. In thesimilar process, values of excess isentropic compressibility $\left(\beta_{s}^{E}\right)$, excess intermolecular free length $\left(L_{f} E\right)$, excess acoustic impedance $\left(Z^{E}\right)$, deviation in viscosity $(\Delta \eta)$ and excess dielectric constant $\left(\varepsilon^{E}\right)$ have been calculated using the general relation

$$
A^{E}=A-\sum_{i=1}^{n} x_{i} A_{i}
$$

where $A$ represents the above mentioned mixture properties and $A_{i}$ represents the properties of the individual components.

Depending upon the viscosity of the binary mixtures of benzene+ (hexane/heptane) excess Gibb's free energy $\left(G^{E}\right)$ of activation of viscous 


\section{Sanghamitra Pradhan, Manaswini Chhotaray, Sujata Mishra}

flow of the binary mixtures have been calculated using the following expressions.

$$
\begin{aligned}
& G^{E}=R T\left[\ln \eta_{\text {mix }} V_{\text {mix }}-\left(X_{1} \ln \eta_{1} V_{1}+\right.\right. \\
& \left.\left.X_{2} \ln \eta_{2} V_{2}\right)\right]
\end{aligned}
$$

Where $\eta_{\text {mix }}, V_{\text {mix }}$ represent the viscosity and volume of the binary mixtures, $\eta_{1}$ and $\eta_{2}$ symbolize the viscosity of benzene and hexane/heptane respectively.

Table 2 and 3 list the density (e), ultrasonic velocity $(\mathrm{U})$, viscosity $(\eta)$ and dielectric constant $(\varepsilon)$ values for binary mixture of benzene + (hexane/heptane) at $\mathrm{T}=(298.15 \mathrm{~K}, 308.15 \mathrm{~K}$ and $318.15 \mathrm{~K}$ ) and demonstrate that the values for all the properties decrease with increase in temperature and increase with rise in mole fraction of benzene.Table 4 presents the comparison of experimental density measurements of binary mixtures of benzene and hexane with the available literature for different mole fractions of benzene.

\subsection{Mixing rules for ultrasonic velocity and dielectric permittivity}

To predict the values of ultrasonic velocity and dielectric constants of the binary mixtures at varied temperatures, various mixing rules were formulated by several researchers [11]. In the present investigation, two mixing rules have been tested for ultrasonic velocity as proposed by Rao and Berryman. Kraszewski and Looyenga proposed rules have been adopted to calculate the dielectric mixing values

$$
\begin{aligned}
& \text { Ultrasonic velocity } \\
& \text { Rao (R) } \\
& U^{1 / 3} V=\sum_{i=1}^{2} U_{i}^{1 / 3} X_{i} V_{i}
\end{aligned}
$$

$$
\begin{aligned}
& \text { Berryman (B) } \\
& U=\left(\rho \sum_{i=1}^{2} \varphi_{i} \beta_{s i}\right)^{-1 / 2}
\end{aligned}
$$

\section{Dielectric permittivity}

Kraszewski $(\mathrm{Kz})$

$$
\varepsilon^{1 / 2}=\varphi_{1} \varepsilon_{1}^{1 / 2}+\varphi_{2} \varepsilon_{2}^{1 / 2}
$$

\section{Results and Discussion}

\subsection{Excess molar volume $\left(\mathrm{V}^{\mathrm{E}}\right)$}

To elucidate the observed trend of $V^{E}$ for binary mixtures of benzene + (hexane/heptane), the plot of $V^{E}$ against mole fraction of benzene at

Looyenga (L)

$\varepsilon=\left[\varepsilon_{1}^{1 / 3}+\varphi_{2}\left(\varepsilon_{2}^{\frac{1}{3}}-\varepsilon_{1}^{\frac{1}{3}}\right)\right]^{3}$

Where $\varepsilon_{1}, \varepsilon_{2}, \varphi_{1}, \varphi_{2}$ are dielectric permittivity and volume fractions of hexane/heptane and benzene, respectively.

The volume fractions, $\varphi_{1}, \varphi_{2}$ are calculated as,

$$
\varphi_{i}=X_{i} V_{i} /\left(\sum_{i=1}^{2} X_{i} V_{i}\right)
$$

Where, $\mathrm{V}_{\mathrm{i}}$ is the molar volume of the $\mathrm{i}^{\text {th }}$ component.

Tables 5 and 6 present the root mean square deviation values between the experimental and calculated data for ultrasonic and dielectric measurements obtained using the mixing rules for both the binary mixtures at $\mathrm{T}=298.15 \mathrm{~K}, 308.15 \mathrm{~K}$ and $318.15 \mathrm{~K}$. The equations proposed by Rao and Berryman for ultrasonic measurements offer best results for benzene and heptane binary mixtures at measured temperatures in comparison to benzenehexane binary mixtures. Kraszewski model works better for dielectric measurements in contrast to Looyenga model in cases of both the mixtures.

The excess values obtained from experimental results were fitted by method of least square with the help of Redlich - Kister polynomial equation and the coefficients, $A j$ 's are calculated by solving the linear equations

$$
\mathrm{Y}^{E}=X_{i}\left(1-X_{i}\right) \sum_{j=0}^{5} A_{j}\left(2 X_{i}-1\right)^{j}(12)
$$

where $Y^{E}$ implies the values of the excess properties $\left(V^{E}, \beta s^{E}, L f^{E}, Z^{E}, \Delta \eta, \varepsilon^{E}\right)$. X $X_{i}$ signifies the mole fraction of benzene, $A_{j}$ is the polynomial coefficients and $j$ refers to the polynomial degree respectively. The standard deviations, $\sigma$ have been calculated using experimental and calculated values by the following equation.

$$
\sigma\left(Y^{\mathrm{E}}\right)=\left[\sum\left(Y_{\text {exp }}^{E}-Y_{\text {cal }}^{E}\right)^{2} /(n-p)\right]^{1 / 2}(13)
$$

$\mathrm{T}=(298.15 \mathrm{~K}, 308.15 \mathrm{~K}$ and $318.15 \mathrm{~K})$ is displayed in Figures $1 \mathrm{a}$ and $1 \mathrm{~b}$. It is clear from figure 1a that values of $V^{E}$ are negative in hexane rich region for binary mixture of benzene + hexane at the 


\section{An Insight on Thermophysical Properties of Binary Mixtures of Hydrocarbons with Spectroscopic Evidence; Essential Components of Transformer Oils}

measured temperatures and gradually become positive with rise in mole fraction of benzene. At low mole fraction region of benzene, the hexane molecules tend to remain in allied form giving rise to negative $V^{E}$. But as the concentration of benzene increases above 0.3 mole fraction there is positive $V^{E}$ leading to rupture of homo-molecular interactions. This indicates that linked hexane molecules are thought to be dissociated in presence of planar rings of benzene molecules leading to expansion in volume. This observation is in accord with Lal et al. [7].
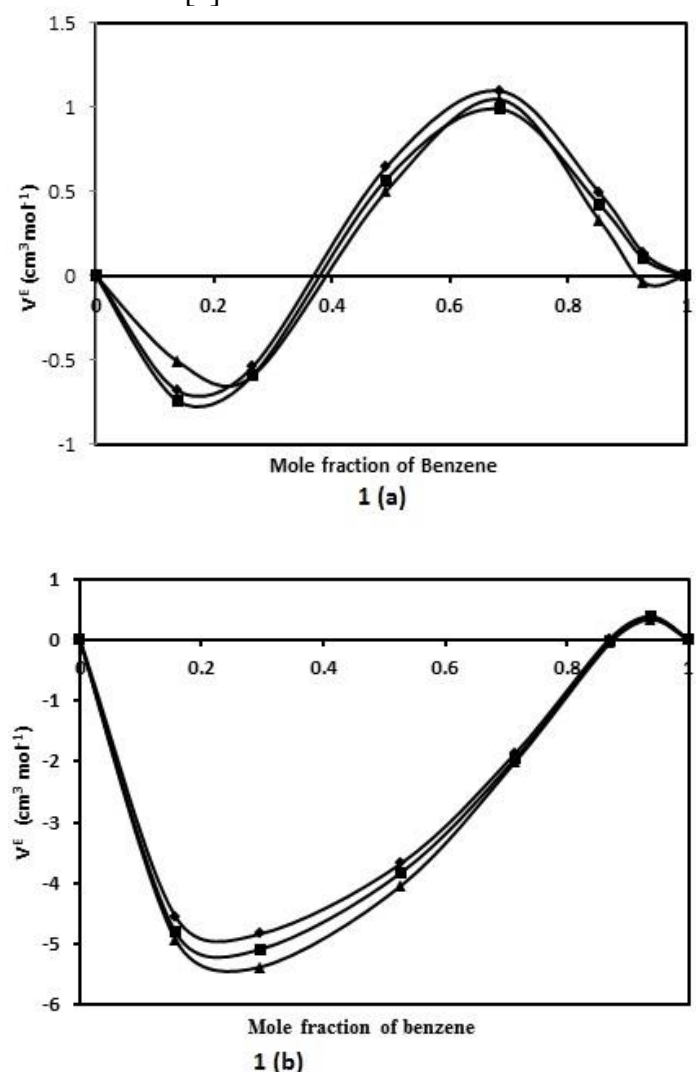

Figure 1. (a) Representation of excess molar volume of benzene + hexane binary mixture and 1(b) benzene + heptane binary mixture at $\mathrm{T}=(298.15$, 308.15 and A $318.5 \mathrm{~K})$.

Kasahara et al. have also stated that the selfdiffusion coefficients (D) of hexane and benzene are close to each other in the lower mole fraction range of hexane $\left(X_{1}<0.4\right)$. But when the mole fraction of hexane increases the hexane molecules tend to translate among themselves [8]. But in case of benzene + heptane binary mixture represented in Figure $1 \mathrm{~b}$, it is noticed that $V^{E}$ curve recorded at mentioned temperatures decrease sharply and passes through a minima at $X_{2} \sim 0.3$ and then further increase with rise in mole fraction of benzene. Negative $V^{E}$ values indicate net packing effect contributed by structural changes arising from interstitial spacing due to difference in size and effect of additional $\mathrm{CH}_{2}$ group present in the heptane molecules [9].

\subsection{Deviations in viscosity $(\Delta \eta)$}

Deviations in viscosity $(\Delta \eta)$ provide qualitative evidence about the molecular associations and become positive when the strength of the interaction increases.
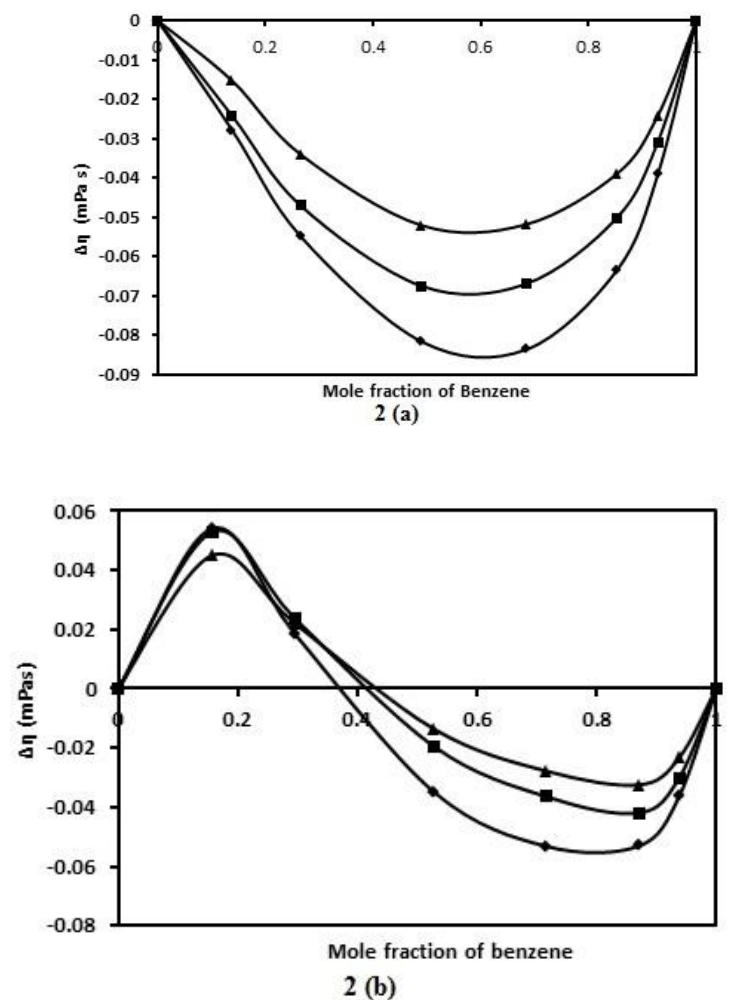

Figures 2. (a) Representation of deviation in viscosity of benzene + hexane binary mixtures and 2 (b) benzene + heptane binary mixture at $\mathrm{T}=(\boldsymbol{2} 29.15, \mathbf{a} 308.15$ and ( $318.5 \mathrm{~K})$.

This may be due to charge transfer complexes or hydrogen bond formation. Negative values for $\Delta \eta$ are obtained due to variation in size and shape of the components and less dipolar interactions in pure components. In the current investigation, the variations in viscosity $(\Delta \eta)$ for binary mixtures of benzene + hexane/heptane against mole fraction of benzene are shown in Figures $2 \mathrm{a}$ and $2 \mathrm{~b}$ at three investigating 
temperatures. Values of $\Delta \eta$ are negative for the complete composition range in benzene + hexane binary mixture whereas for benzene + heptane mixtures a negative trend is observed above 0.4 mole fraction of benzene from 298.15 to $318.15 \mathrm{~K}$. A minimum is observed at $X_{2} \sim 0.6$ for benzenehexane and $X_{2} \sim 0.8$ for benzene-heptane systems. Negative deviations in viscosity observed at measured temperatures reveal the strength of nonspecific interactionand variance in size and figure of the constituents in the binary mixture.

\subsection{Excess isentropic compressibility $\left(\beta_{\mathrm{s}}^{\mathrm{E}}\right)$, free length $\left(L_{f}{ }^{E}\right)$ and acoustic impedance $\left(\mathrm{Z}^{\mathrm{E}}\right)$}

Graphical representations of the values of $\beta \mathrm{s}^{\mathrm{E}}$ as a function of mole fraction of benzene for the investigated binary mixtures are presented in Figures $3 \mathrm{a}$ and $3 \mathrm{~b}$.
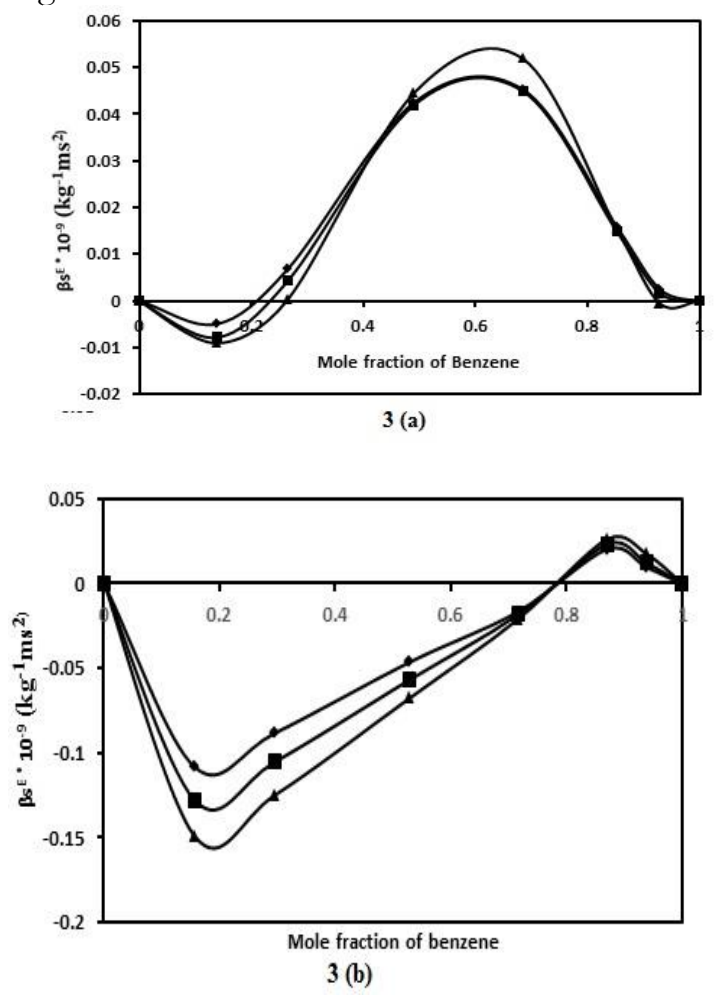

Figure 3. (a) Representation of isentropic compressibility $\left(\beta_{\mathrm{s}}^{\mathrm{E}}\right)$ of benzene + hexane binary mixtures and 3 (b) benzene + heptane binary mixture as a function of mole fraction of benzene at $\mathrm{T}=(\mathbf{2 9 8 . 1 5}$, - 308.15 and $\boldsymbol{\Delta} 318.5 \mathrm{~K})$.

The curves highlighted in both the cases show that the behaviour of $\beta_{\mathrm{s}}^{\mathrm{E}}$ at all compositions in the binary mixtures are reflected in that of $\mathrm{Lf}_{\mathrm{f}}{ }^{\mathrm{E}}$ (Figures $4 \mathrm{a}$ and $4 \mathrm{~b}$ ). Both $\beta_{\mathrm{s}} \mathrm{E}$ and $\mathrm{L}_{\mathrm{f}}^{\mathrm{E}}$ are positive above $\mathrm{X}_{2}=0.2$ for the binary mixture of benzene and hexane. The positive deviation of $\beta_{\mathrm{s}}^{\mathrm{E}}$ and $\mathrm{L}_{\mathrm{f}}^{\mathrm{E}}$ indicate feeble interaction comprising weak dispersion forces between distinct molecules in the binary mixture. This observation is well supported by the values of $\mathrm{V}^{\mathrm{E}}$ measured at all temperatures. Intermolecular free length is used to examine the attraction between the component molecules in the binary mixture and as the temperature rises, the intermolecular attraction decreases due to thermal agitation. The results are supported by the observation that temperature increase consequences in increase in distance between the molecules in liquids thereby enhancing the space between the surfaces of the molecules [11]. With rise in temperature it is noted that the density of the binary mixture gradually decreases as a result of increase in free length between the constituents in the binary mixture.
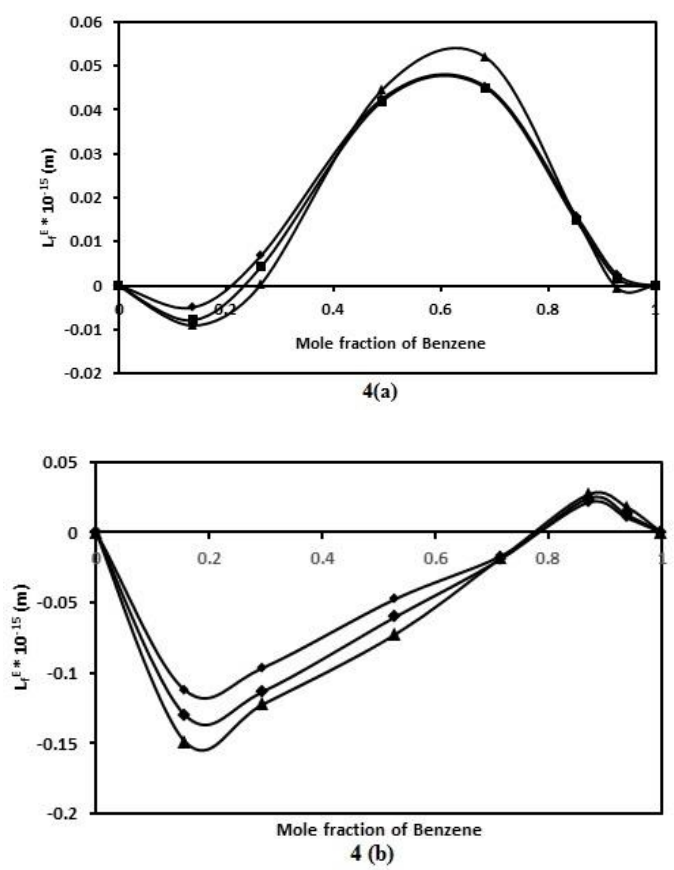

Figure 4. (a) Plot of $\mathrm{L}_{\mathrm{f}}^{\mathrm{E}}$ of benzene + hexane binary mixtures and 4 (b) benzene + heptane binary mixture as a function of molefraction of benzene at $\mathrm{T}=(\boldsymbol{2} 298.15$, - 308.15 and $\mathbf{\Delta} 318.5 \mathrm{~K})$.

But in case of benzene + heptane binary mixture, $\beta_{\mathrm{s}}^{\mathrm{E}}$ values are negative. This indicates good compressibility between the unlike components of the binary mixture resulting in decreasing in $\mathrm{L}_{\mathrm{f}} \mathrm{E}$. These findings are in turn reinforced by the negative $\mathrm{VE}$ values. 


\section{An Insight on Thermophysical Properties of Binary Mixtures of Hydrocarbons with Spectroscopic Evidence; Essential Components of Transformer Oils}

The curves of $\mathrm{Z}^{\mathrm{E}}$ for binary mixtures of benzene + (hexane/heptane) represented in Figures $5 \mathrm{a}$ and $5 \mathrm{~b}$ show opposite trend as observed for $\beta_{\mathrm{s}}^{\mathrm{E}}$ and $\mathrm{Lf}_{\mathrm{f}}^{\mathrm{E}}$. In case of benzene + hexane binary mixture, the negative $Z^{\mathrm{E}}$ values can be attributed to weak dipolar interaction as observed in case of $\mathrm{VE}^{\mathrm{E}}$, $\beta_{\mathrm{s}} \mathrm{E}$ and $\mathrm{L}_{\mathrm{f}} \mathrm{E}$. But in case of benzene theptane binary mixture the trend is opposite giving rise to positive $\mathrm{Z}^{\mathrm{E}}$ values indicating specific interaction between the dissimilar components in the binary mixture. Similar observations have been made in the examination of temperature reliance ultrasonic velocity measurements for certain binary liquid mixtures where increase in temperature reduces the interaction between the components in the binary mixture due to thermal stress [16]. This is evident from the reduction in ultrasonic velocity and viscosity values recorded at higher temperatures resulting due to breaking of hetero and homo molecular clusters.
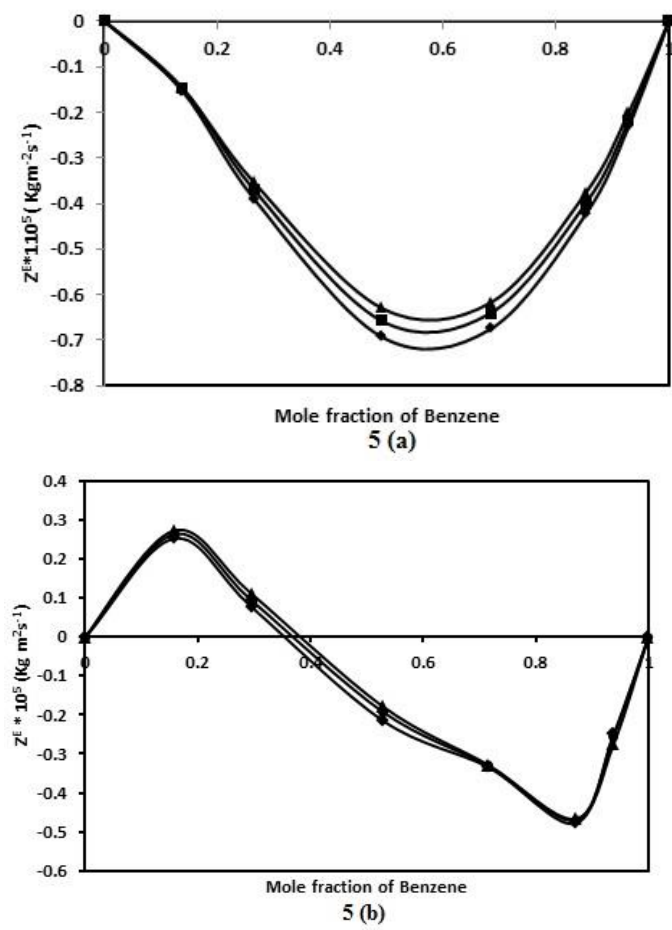

Figure 5. (a) Representation of $\mathrm{Z}^{\mathrm{E}}$ of benzene + hexane binary mixtures and 4(b) benzene + heptane binary mixture as a function of mole fraction of benzene at $\mathrm{T}=$ $(\bullet 298.15$, $\mathbf{\square} 308.15$ and $\boldsymbol{\Delta} 318.5 \mathrm{~K})$.

\subsection{Excess dielectric permittivity $\left(\varepsilon^{\mathrm{E}}\right)$}

Measurements of dielectric permittivity serve as an important technique for elucidating intra and intermolecular associations due to dipole interactions. It is an intrinsic property and plays vital role in solution [17]. The excess permittivity values of the binary mixtures of benzene + hexane/heptane furnish qualitative information about molecular interactions; if $\varepsilon^{\mathrm{E}}=0$, then there is no interaction between the unlike components, if $\varepsilon^{\mathrm{E}<0}$, multimers are formed leading to formation of less effective dipoles but effective dipolar polarization between the unlike components increases when $\varepsilon^{\mathrm{E}}>0$.
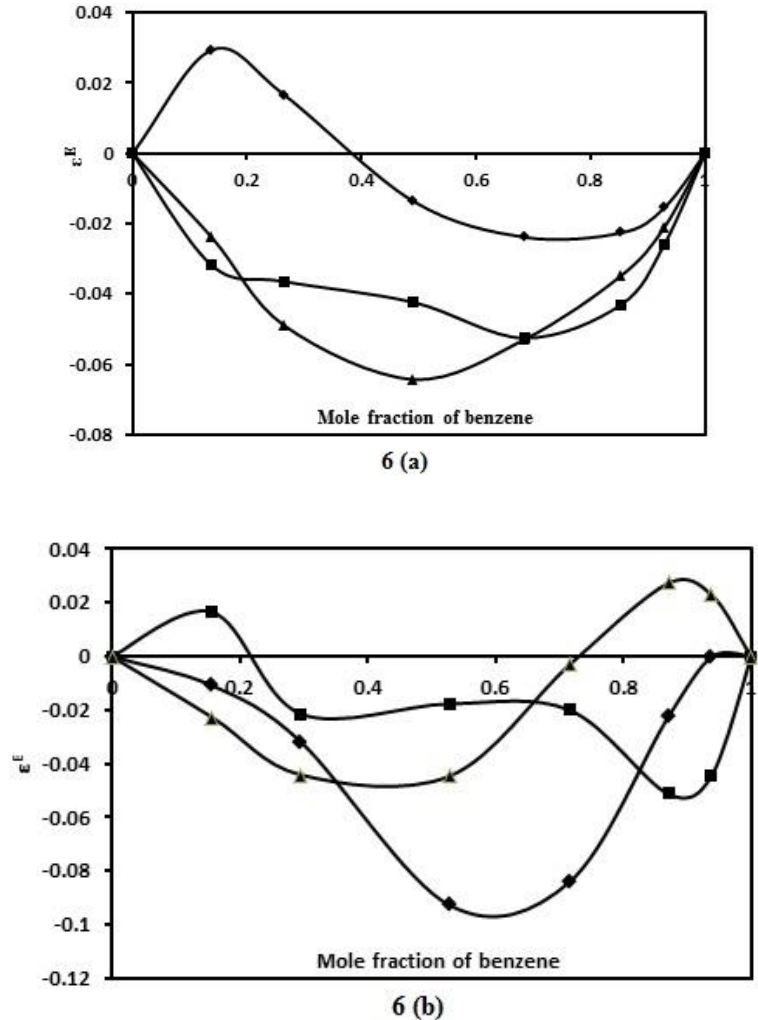

Figures 6 (a) Representation of $\varepsilon^{\mathrm{E}}$ of benzene + hexane for binary mixture and $6(\mathrm{~b})$ benzene + heptane binary mixture as a function of mole fraction of benzene at $\mathrm{T}=$ $(\bullet 298.15$, 308.15 and $\boldsymbol{\Delta} 318.5 \mathrm{~K})$.

The plot of excess permittivity against mole fraction of benzene for binary mixture of benzene + (hexane / heptane) at $\mathrm{T}=298.15 \mathrm{~K}, 308.15 \mathrm{~K}$ and $318.15 \mathrm{~K}$ are represented in Figures $6 \mathrm{a}$ and $6 \mathrm{~b}$. In this investigation the excess permittivity values in case of benzene + hexane binary mixture at 298.15K appears to be positive indicating increase in effective correlation dipoles in hexane rich region. But with increase in temperature the values of $\varepsilon^{\mathrm{E}}$ become negative leading to decrease in effective dipoles. While in case of benzene + heptane binary mixture the values of $\varepsilon^{\mathrm{E}}$ at all temperatures appears to be negative indicating polar associations formed with lower dipole moments 


\section{Sanghamitra Pradhan, Manaswini Chhotaray, Sujata Mishra}

due to orientation of some of the neighbouring dipoles in the opposite direction.It becomes slightly positive in benzene rich region at $308.15 \mathrm{~K}$ which may be due to homo-molecular linkage of benzene molecules.

The polynomial coefficients $A_{0}, A_{1}, A_{2}$ and $A_{3}$ as well as standard deviation $\sigma$ for the excess properties are given in Table 7 and 8 . By inspecting the $\sigma$ values, it can be assumed that terminologies utilised for including the experimental findings yield good results

\subsection{Excess Gibb's free energy of activation} of viscous flow $\left(\mathrm{G}^{\mathrm{E}}\right)$

The variation of Gibb's energy of viscous flow $\left(\mathrm{G}^{\mathrm{E}}\right)$ with mole fraction of benzene for both the binary mixtures benzene + (hexane/heptane) at varied temperatures are represented in Figures $7 \mathrm{a}$ and $7 \mathrm{~b}$.
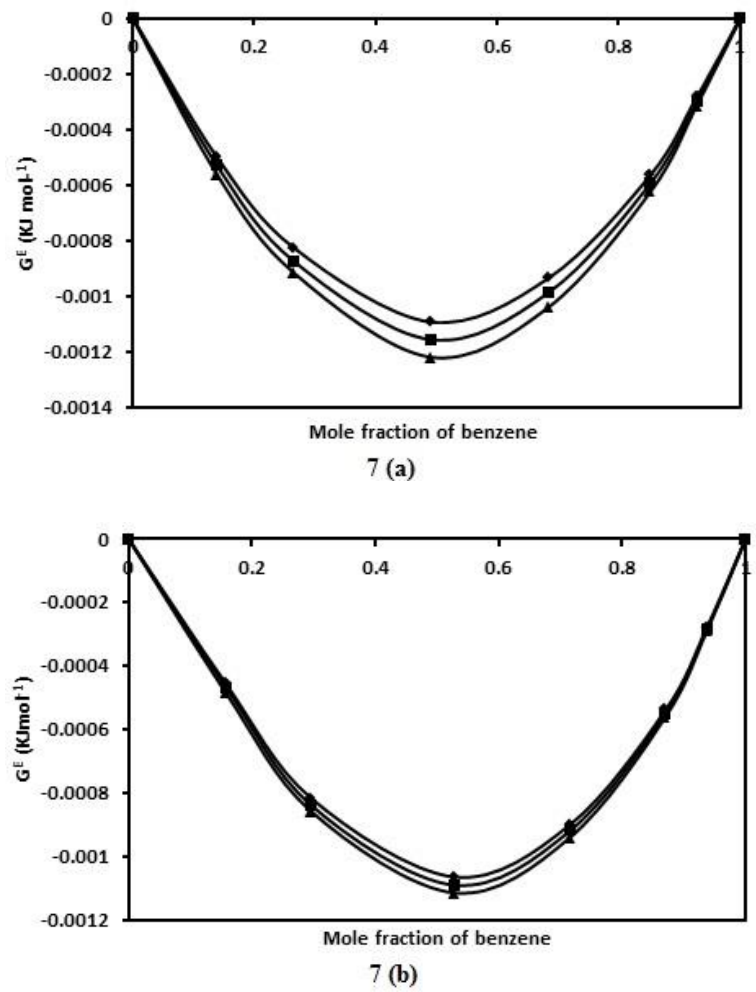

Figures 7. (a) Representation of $\mathrm{G}^{\mathrm{E}}$ of benzene + hexane for binary mixture and 7(b) benzene + heptane for binary mixture at $\mathrm{T}=(\mathbf{2 9 8 . 1 5}, \mathbf{\square} 308.15$ and $\boldsymbol{\Delta} 318.5 \mathrm{~K})$.

The values $\mathrm{G}^{\mathrm{E}}$ are found to be negative over the entire composition range at measured temperatures. In a binary mixture of two nonpolar components, the first molecule undergo changes in position of electrons and acquires instantaneous dipole moment and tries to polarize the other component present in its vicinity and induces dipole moment in the second one. The resultant dipoles attract one another leading to a minimum potential energy. In general, positive trend of excess Gibb's free energy indicate specific interaction while negative contributions can be attributed to the dispersion forces existing between unlike components in the binary mixture [18]. In the $G^{\mathrm{E}}$ values for both the mixtures indicate the existence of dispersion force in the system supported by the negative $\eta^{\mathrm{E}}$ values.

\subsection{Spectroscopic Techniques}

To examine the precision of qualitative interpretations such as excess volume, ultrasonic velocity, viscosity and dielectric measurements, spectroscopic techniques like FTIR and NMR have been used.

\subsection{FTIR analysis}

FTIR spectroscopy has been broadly utilised to elucidate the intermolecular interactions between the unlike components in the binary mixture. Figure 8 depicts the FT-IR spectra recorded for benzene + hexane/heptane binary mixtures at $\mathrm{X}_{2}=0.49$ and 0.52 mole fractions respectively. The measured physico chemical properties of these binary mixtures exhibit negligible effect of temperature. So FT-IR analysis has been performed at 298.15K. Generally aromatic hydrocarbons exhibit characteristic absorption peaks in the range of 3100 - $3000 \mathrm{~cm}^{-1}$ due to $-\mathrm{CH}$ stretch stretching. Specifically in pure benzene two distinct peaks are visible at $1959 \mathrm{~cm}^{-1}$ and $1814 \mathrm{~cm}^{-1}$ arising from the C-C stretching vibrations in the benzene ring [19].

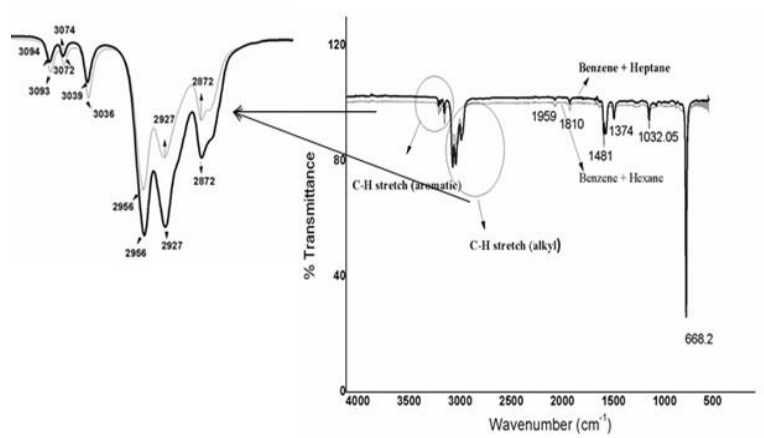

Figure 8. Representation of FT-IR spectrum benzene + hexane/heptane binary mixtures at $298.15 \mathrm{~K}$.

It is observed that when benzene is mixed with hydrocarbons like hexane and heptane, the effect of the solvents are almost same with a slight shift from $1814 \mathrm{~cm}^{-1}$ to $1810 \mathrm{~cm}^{-1}$. A close examination of the 


\section{An Insight on Thermophysical Properties of Binary Mixtures of Hydrocarbons with Spectroscopic Evidence; Essential Components of Transformer Oils}

spectra reveals that for both the binary mixtures there are changes in intensities in the range of 3100 $-3000 \mathrm{~cm}^{-1}$ which arise due to $-\mathrm{C}-\mathrm{H}$ stretching of the aromatic ring and alkyl C-H stretching in the region of $2872-2956 \mathrm{~cm}^{-1}$. This observation is in coherence with positive and negative excess molar volume where the benzene molecules translate with hexane/heptane molecules in the higher mole range of benzene whereas the aliphatic hydrocarbons translate among themselves in the lower mole fraction range of benzene.

\subsection{NMR analysis}

${ }^{1} \mathrm{H}$ NMR spectroscopic technique is used to have better understanding about the structural organisation of the unlike components in the binary mixture of benzene + hexane/heptane at $\mathrm{T}=$ 298.15K represented in Figures 9a and 9b. For benzene, singlet is observed in the range of 7.4 and $7.5 \mathrm{ppm}$. To elucidate the attractive interaction between benzene and hexane/heptane molecules, the chemical shifts have been measured to identify the association between the unlike components. In the present case, if there is any attractive association between benzene and hexane/heptane molecules, the resulting chemical shift will move downfield. From the spectrum which is recorded at $\mathrm{X}_{2}=0.49$ and 0.52 mole fractions of benzene with hexane and heptane respectively, it is detected that there are slight changes in chemical shifts of methylene protons. Normally in pure hexane/heptane the chemical shift for methylene protons is $1.27 \mathrm{ppm}$. In case of binary mixtures of benzene + hexane/heptane, there is shift to $1.342 \mathrm{ppm}$. It has already been reported that methylene group of hexane molecules interact with the $\pi$ electrons of the benzene ring more actively than the methyl protons [8]. This is so because the distance between the methylene group and the benzene ring is closer in comparison to methyl group. In the present case sharp methylene peaks are observed in case of benzene + hexane binary mixture since the rate of interaction in NMR time scale is fast but broad peaks are observed in benzene + heptane as the interaction time gets enhanced due to the presence of additional $\mathrm{CH}_{2}$ group in heptane in comparison to hexane molecules.
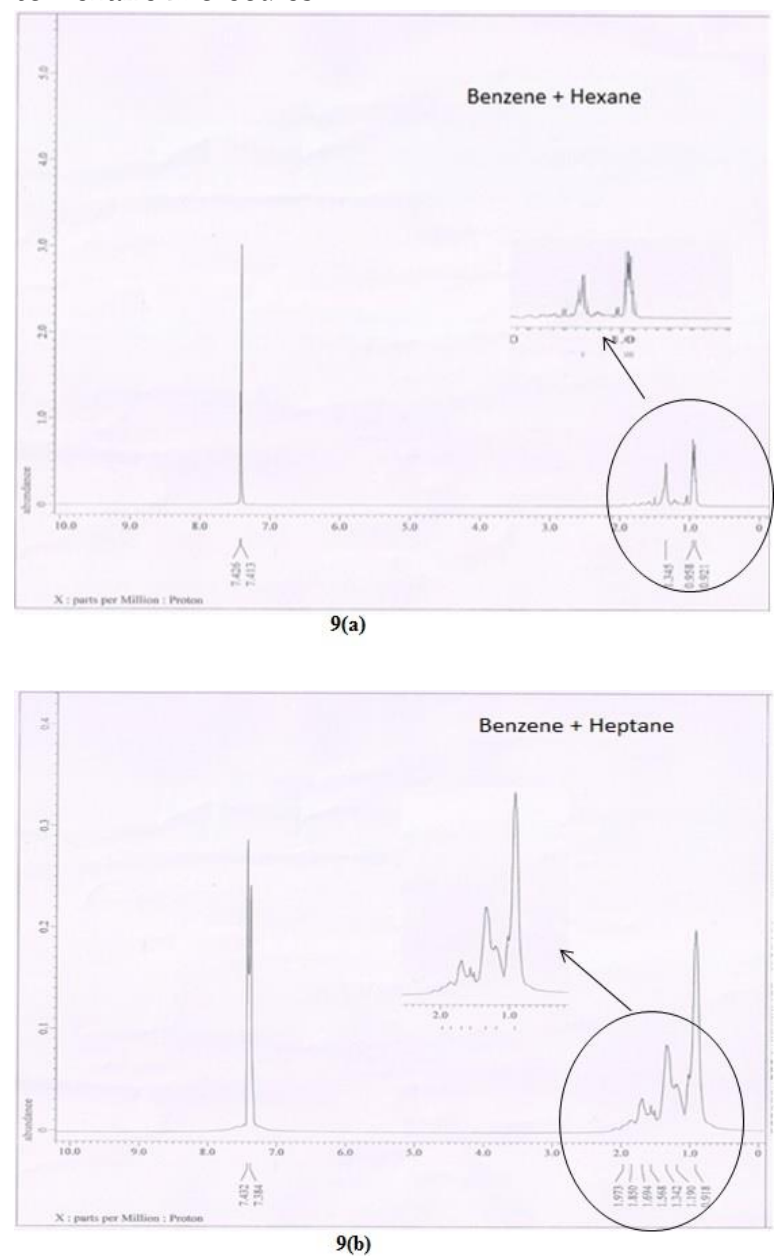

Figure 9. (a) ${ }^{1} \mathrm{H}$ NMR spectrum of benzene + hexane binary mixture and $9(\mathrm{~b})$ forbenzene + heptane binary mixture.

Table 2. Experimental density (e), ultrasonic velocity $(\mathrm{U})$, viscosity $(\eta)$ and dielectric constant $(\varepsilon)$ for binary mixture of benzene + hexane at $\mathrm{T}=(298.15 \mathrm{~K}, 308.15 \mathrm{~K}$ and $318.15 \mathrm{~K})$.

\begin{tabular}{|c|c|c|c|c|}
\hline $\mathbf{X}_{2}$ & $\varrho\left(\right.$ kg.m $\left.{ }^{-3}\right)$ & $\mathrm{U}\left(\mathrm{m} \cdot \mathrm{s}^{-1}\right)$ & $\eta$ (mPa.s) & $\varepsilon$ \\
\hline \multicolumn{5}{|c|}{ Benzene + Hexane (298.15K) } \\
\hline 0 & 667.44 & 1081.29 & 0.3508 & 1.880 \\
\hline 0.1382 & 691.03 & 1098.97 & 0.3582 & 1.941 \\
\hline 0.2652 & 712.30 & 1117.71 & 0.3655 & 1.972 \\
\hline 0.4905 & 744.64 & 1139.91 & 0.394 & 1.990 \\
\hline 0.6841 & 788.56 & 1196.03 & 0.4482 & 2.065 \\
\hline 0.8524 & 825.93 & 1239.03 & 0.5014 & 2.083 \\
\hline 0.9285 & 854.39 & 1274.01 & 0.5598 & 2.140 \\
\hline
\end{tabular}


Sanghamitra Pradhan, Manaswini Chhotaray, Sujata Mishra

\begin{tabular}{|c|c|c|c|c|}
\hline $\mathbf{X}_{2}$ & $\varrho\left(\mathrm{kg} \cdot \mathrm{m}^{-3}\right)$ & $\mathrm{U}\left(\mathrm{m} \cdot \mathrm{s}^{-1}\right)$ & $\eta$ (mPa.s) & $\varepsilon$ \\
\hline \multicolumn{5}{|c|}{ Benzene + Hexane (298.15K) } \\
\hline 1 & 873.48 & 1298.53 & 0.6096 & 2.146 \\
\hline \multicolumn{5}{|c|}{ Benzene + Hexane (308.15K) } \\
\hline 0 & 657.90 & 1035.9 & 0.3296 & 1.860 \\
\hline 0.1382 & 681.59 & 1054.09 & 0.3334 & 1.896 \\
\hline 0.2652 & 702.74 & 1072.93 & 0.3388 & 1.932 \\
\hline 0.4905 & 734.73 & 1096.2 & 0.362 & 2.041 \\
\hline 0.6841 & 778.52 & 1150.83 & 0.4084 & 2.105 \\
\hline 0.8524 & 815.62 & 1193.64 & 0.4515 & 2.188 \\
\hline 0.9285 & 843.84 & 1228.06 & 0.4979 & 2.252 \\
\hline 1 & 862.75 & 1251.90 & 0.5376 & 2.299 \\
\hline \multicolumn{5}{|c|}{ Benzene + Hexane (318.15K) } \\
\hline 0 & 648.46 & 990.84 & 0.3021 & 1.840 \\
\hline 0.1382 & 670.97 & 1010.42 & 0.3102 & 1.864 \\
\hline 0.2652 & 693.03 & 1028.43 & 0.3169 & 1.880 \\
\hline 0.4905 & 724.64 & 1052.28 & 0.3348 & 1.944 \\
\hline 0.6841 & 768.36 & 1106.10 & 0.3755 & 2.017 \\
\hline 0.8524 & 805.20 & 1148.62 & 0.4104 & 2.098 \\
\hline 0.9285 & 833.21 & 1182.73 & 0.4481 & 2.131 \\
\hline 1 & 851.95 & 1206.25 & 0.4803 & 2.180 \\
\hline
\end{tabular}

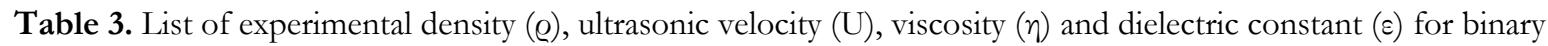
mixture of benzene + heptane at $\mathrm{T}=(298.15 \mathrm{~K}, 308.15 \mathrm{~K}$ and $318.15 \mathrm{~K})$.

\begin{tabular}{|c|c|c|c|c|}
\hline $\mathbf{X}_{2}$ & $\varrho\left(\mathrm{kg} \cdot \mathrm{m}^{-3}\right)$ & $\mathrm{U}\left(\mathrm{m} \cdot \mathrm{s}^{-1}\right)$ & $\eta(\mathrm{mPa} . \mathrm{s})$ & $\varepsilon$ \\
\hline \multicolumn{5}{|c|}{ Benzene + Heptane (298.15K) } \\
\hline 0 & 679.21 & 1080.85 & 0.3370 & 1.900 \\
\hline 0.1572 & 710.60 & 1141.73 & 0.4377 & 2.004 \\
\hline 0.2956 & 735.67 & 1156.6 & 0.4436 & 2.023 \\
\hline 0.5281 & 772.99 & 1187.44 & 0.4535 & 2.166 \\
\hline 0.7158 & 806.49 & 1219.33 & 0.4820 & 2.243 \\
\hline 0.8704 & 829.56 & 1245.11 & 0.5164 & 2.301 \\
\hline 0.9379 & 852.52 & 1271.05 & 0.5586 & 2.349 \\
\hline 1 & 873.48 & 1298.53 & 0.6096 & 2.146 \\
\hline \multicolumn{5}{|c|}{ Benzene + Heptane (308.15K) } \\
\hline 0 & 671.94 & 1035.72 & 0.3140 & 1.880 \\
\hline 0.1572 & 701.84 & 1097.81 & 0.4025 & 1.903 \\
\hline 0.2956 & 726.69 & 1112.74 & 0.4035 & 1.927 \\
\hline 0.5281 & 763.48 & 1143.2 & 0.4126 & 1.992 \\
\hline 0.7158 & 796.48 & 1172.3 & 0.4387 & 2.088 \\
\hline 0.8704 & 819.38 & 1197.88 & 0.4641 & 2.145 \\
\hline 0.9379 & 842.07 & 1223.15 & 0.4978 & 2.153 \\
\hline 1 & 862.75 & 1251.99 & 0.5376 & 2.299 \\
\hline \multicolumn{5}{|c|}{ Benzene + Heptane (318.15K) } \\
\hline 0 & 658.51 & 990.84 & 0.2940 & 1.86 \\
\hline 0.1572 & 692.08 & 1054.81 & 0.3688 & 1.890 \\
\hline 0.2956 & 717.88 & 1070.38 & 0.3707 & 1.906 \\
\hline 0.5281 & 753.88 & 1099.47 & 0.3792 & 1.906 \\
\hline 0.7158 & 786.27 & 1126.6 & 0.4002 & 1.968 \\
\hline 0.8704 & 809.11 & 1151.64 & 0.4223 & 2.062 \\
\hline 0.9379 & 831.53 & 1174.55 & 0.4484 & 2.116 \\
\hline 1 & 851.95 & 1206.25 & 0.4803 & 2.180 \\
\hline
\end{tabular}




\section{An Insight on Thermophysical Properties of Binary Mixtures of Hydrocarbons with Spectroscopic Evidence; Essential Components of Transformer Oils}

Table 4. Comparison of experimental density values measured using digital density meter with the literature values recorded using pycnometer for binary mixtures of benzene - hexane system at $298.15 \mathrm{~K}$

\begin{tabular}{c|c|l}
\hline $\mathbf{X}_{2}$ & $\begin{array}{c}\varrho(\text { g.cm } \\
(\mathbf{e x p})\end{array}$ & $\varrho($ g.cm \\
& $0.7123)(\mathbf{l i t})$ \\
\hline 0.2652 & 0.74464 & $\mathrm{X}_{2}=0.21, \varrho=0.6837[8] ; \mathrm{X}_{2}=0.218, \varrho=0.688[7$ \\
\hline 0.4905 & 0.78856 & $\mathrm{X}_{2}=0.40, \varrho=0.7148[8] ; \mathrm{X}_{2}=0.493, \varrho=0.7391[7]$ \\
\hline 0.6841 & 0.82593 & $\mathrm{X}_{2}=0.80, \varrho=0.808[8] ; \mathrm{X}_{2}=0.84, \varrho=0.8434[7$ \\
\hline 0.850 & \multicolumn{2}{|l}{} \\
\hline
\end{tabular}

Table 5. Representation of root mean square deviation (RMSD) of ultrasonic and dielectric constant for binary mixture of benzene + hexane at $\mathrm{T}=298.15 \mathrm{~K}, 308.15 \mathrm{~K}$ and $318.15 \mathrm{~K}$.

\begin{tabular}{|c|c|c|c|c|c|c|}
\hline Properties & \multicolumn{4}{|c|}{ RMSD } & & \\
\hline Temperature $(\mathrm{K})$ & \multicolumn{2}{|c|}{$298.15 \mathrm{~K}$} & \multicolumn{2}{|c|}{$308.15 \mathrm{~K}$} & \multicolumn{2}{|c|}{$318.15 \mathrm{~K}$} \\
\hline \multicolumn{7}{|c|}{ Benzene + Hexane } \\
\hline \multirow[t]{2}{*}{$\mathrm{U}$} & $\mathrm{R}$ & $\mathrm{B}$ & $\mathrm{R}$ & B & $\mathrm{R}$ & B \\
\hline & 0.19615 & 0.12953 & 0.24017 & 0.11894 & 0.22843 & 0.95268 \\
\hline \multirow[t]{2}{*}{$\varepsilon$} & $\mathrm{Kz}$ & $\mathrm{L}$ & $\mathrm{Kz}$ & $\mathrm{L}$ & $\mathrm{Kz}$ & $\mathrm{L}$ \\
\hline & 0.01870 & 0.03753 & 0.02538 & 0.04974 & 0.02147 & 0.04166 \\
\hline
\end{tabular}

Table 6. Representation of root mean square deviation (RMSD) of ultrasonic and dielectric constant for binary mixture of benzene + heptane at $\mathrm{T}=298.15 \mathrm{~K}, 308.15 \mathrm{~K}$ and $318.15 \mathrm{~K}$.

\begin{tabular}{|c|c|c|c|c|c|c|}
\hline Properties & \multicolumn{4}{|c|}{ RMSD } & & \\
\hline Temperature $(\mathrm{K})$ & \multicolumn{2}{|c|}{$298.15 \mathrm{~K}$} & \multicolumn{2}{|c|}{$308.15 \mathrm{~K}$} & \multicolumn{2}{|c|}{$318.15 \mathrm{~K}$} \\
\hline \multicolumn{7}{|c|}{ Benzene + Heptane } \\
\hline \multirow[t]{2}{*}{$\mathrm{U}$} & $\mathrm{R}$ & B & $\mathrm{R}$ & B & $\mathrm{R}$ & B \\
\hline & 0.03960 & 0.002069 & 0.04020 & 0.002053 & 0.040715 & 0.00202 \\
\hline \multirow[t]{2}{*}{$\varepsilon$} & $\mathrm{Kz}$ & $\mathrm{L}$ & $\mathrm{Kz}$ & $\mathrm{L}$ & $\mathrm{Kz}$ & $\mathrm{L}$ \\
\hline & 0.03275 & 0.06601 & 0.01103 & 0.02130 & 0.02409 & 0.04719 \\
\hline
\end{tabular}

Table 7. Redlich-Kister coefficients estimated for binary mixtures of benzene + hexane for derived properties using equation 14 and 15 at $\mathrm{T}=(298.15 \mathrm{~K}, 308.15 \mathrm{~K}$ and $318.15 \mathrm{~K})$.

\begin{tabular}{|c|c|c|c|c|c|c|}
\hline Properties & Temperature/K & $\mathrm{A}_{0}$ & $\mathrm{~A}_{1}$ & $\mathrm{~A}_{2}$ & $\mathrm{~A}_{3}$ & $\sigma$ \\
\hline \multirow{3}{*}{$V^{E}$} & 298.15 & 2.7569 & 9.7620 & -7.1372 & -6.1541 & 0.032531 \\
\hline & 308.15 & 2.4560 & 9.2810 & -7.5745 & -5.2930 & 0.298925 \\
\hline & 318.15 & 2.2077 & 11.0775 & -6.0554 & -12.4666 & 0.047012 \\
\hline \multirow[t]{3}{*}{$\Delta \eta$} & 298.15 & -0.3290 & -0.1036 & -0.0870 & -0.1728 & 0.000015 \\
\hline & 308.15 & -0.2716 & -0.0603 & -0.0637 & -0.1526 & 0.000010 \\
\hline & 318.15 & -0.2097 & -0.0539 & -0.0240 & -0.1446 & 0.000008 \\
\hline \multirow[t]{3}{*}{$\beta s^{E}$} & 298.15 & -0.1589 & -0.2935 & -0.4888 & -0.2730 & 0.000060 \\
\hline & 308.15 & 0.0495 & -0.5261 & 1.5097 & -1.6334 & 0.859580 \\
\hline & 318.15 & -17.79 & -23.905 & 32.700 & 75.645 & 0.519157 \\
\hline \multirow[t]{3}{*}{$L_{f}^{E}$} & 298.15 & 0.1744 & 0.2209 & -0.2612 & -0.2126 & 0.000021 \\
\hline & 308.15 & 0.1724 & 0.2315 & -0.2886 & -0.2118 & 0.000025 \\
\hline & 318.15 & 0.1844 & 0.3190 & -0.3206 & -0.365 & 0.000024 \\
\hline \multirow[t]{3}{*}{$Z^{E}$} & 298.15 & -2.7920 & -1.1489 & 0.8672 & -0.5738 & 0.002862 \\
\hline & 308.15 & -2.6511 & -1.0901 & 0.8411 & -0.5184 & 0.002423 \\
\hline & 318.15 & -2.5392 & -1.1382 & 0.7894 & -0.1443 & 0.002426 \\
\hline \multirow[t]{3}{*}{$\varepsilon^{E}$} & 298.15 & -0.0579 & -0.1715 & 0.1691 & -0.2435 & 0.000200 \\
\hline & 308.15 & -0.1714 & -0.1131 & -0.2613 & 0.1082 & 0.000040 \\
\hline & 318.15 & -0.2563 & 0.0463 & 0.0294 & -0.1958 & 0.000004 \\
\hline
\end{tabular}


Table 8. Coefficients of binary mixture of benzene + heptane for derived properties using equation at $\mathrm{T}=$ (298.15K, 308.15K and 318.15K).

\begin{tabular}{|c|c|c|c|c|c|c|}
\hline Properties & Temperature/K & $\mathrm{A}_{0}$ & $A_{1}$ & $A_{2}$ & $\mathrm{~A}_{2}$ & $\sigma$ \\
\hline \multirow[t]{3}{*}{$V^{E}$} & 298.15 & -15.4281 & 12.8679 & -5.7794 & 22.7316 & 0.033316 \\
\hline & 308.15 & -16.0819 & 13.6866 & -6.7506 & 23.5179 & 0.033643 \\
\hline & 318.15 & -17.0431 & 15.5409 & -6.0244 & 20.5746 & 0.035207 \\
\hline \multirow[t]{3}{*}{$\Delta \eta$} & 298.15 & -0.1232 & -0.3120 & 0.2497 & -0.6234 & 0.000020 \\
\hline & 308.15 & -0.0649 & -0.2475 & 0.2186 & -0.5987 & 0.000003 \\
\hline & 318.15 & -0.0434 & -0.2090 & 0.1878 & -0.4731 & 0.000001 \\
\hline \multirow[t]{3}{*}{$\beta s^{E}$} & 298.15 & -0.1981 & -0.2952 & -0.3474 & 0.7650 & 0.000011 \\
\hline & 308.15 & -0.2399 & 0.3643 & -0.3916 & 0.8721 & 0.000013 \\
\hline & 318.15 & -0.2873 & 0.4369 & -0.4387 & 1.0024 & 0.000009 \\
\hline \multirow[t]{3}{*}{$L_{f}^{E}$} & 298.15 & -0.2117 & 0.3477 & -0.3502 & 0.7176 & 0.000010 \\
\hline & 308.15 & -0.2617 & -0.3601 & 0.7917 & -0.2617 & 0.000012 \\
\hline & 318.15 & -0.2943 & 0.4359 & -0.3854 & 1.0023 & 0.000017 \\
\hline \multirow[t]{3}{*}{$Z^{E}$} & 298.15 & -0.6922 & -1.7165 & -0.0112 & -4.5595 & 0.000856 \\
\hline & 308.15 & -0.6137 & -1.7932 & 0.0751 & -4.4731 & 0.000659 \\
\hline & 318.15 & -0.5492 & -1.8267 & -0.1566 & -4.5771 & 0.000412 \\
\hline \multirow[t]{3}{*}{$\varepsilon^{E}$} & 298.15 & -0.349 & -0.4328 & 0.3791 & 0.6455 & 0.000045 \\
\hline & 308.15 & -0.0829 & 0.2241 & -0.0716 & -1.2253 & 0.000276 \\
\hline & 318.15 & -0.1917 & 0.2021 & 0.4247 & 0.1263 & 0.000015 \\
\hline
\end{tabular}

\section{Conclusions}

The acoustic data, density, viscosity, dielectric constants and other related thermodynamic properties of binary mixtures of benzene thexane/heptane at $\mathrm{T}=298.15,308.15$ and $318.15 \mathrm{~K}$ are recorded and presented in this manuscript. With the help of experimental data for all binary systems at measured temperatures, the excess properties have been determined and fitted to Redlich-Kister polynomial equation to examine the quality of experimental findings. From the calculated standard deviation values, it can be interpreted that obtained results are good. The positive $\mathrm{V}^{\mathrm{E}}$ predicts homo-molecular molecular interactions. But in case of benzene + heptane, the positive $V^{E}$ above $\mathrm{X}_{2}=0.8$ suggests that interstitial accommodation is dominant over homo-molecular interactions. A good correlation is observed between $\mathrm{V}^{\mathrm{E}}$ and $\beta_{\mathrm{s}} \mathrm{E} / \mathrm{L}_{\mathrm{f}} \mathrm{E}$ for both binary mixtures at measured temperatures. The trend of deviation in viscosity is similar to $Z^{\mathrm{E}}$. The dielectric measurements for non - polar binary mixtures indicate reduction of dipoles in case of benzene + hexane and opposite orientation of dipoles is detected for benzene + heptane. The theoretical values predicted by Rao and Berryman for ultrasonic measurements of benzene + hexane are good in comparison to benzene + heptane. Kraszewski model fits well for dielectric measurements in comparison to Looyenga. The negative excess $G^{E}$ specify the presence of dispersion interactions between the unlike components. FT-IR and NMR analysis complemented the obtained observations through thermal and acoustic measurements.

However, the attained results offer basic understandings regarding the physico-chemical properties of hydrocarbon binary mixtures without maintaining its proportion as used in transformer oil. Physico-chemical properties control the ability of transformer oil to endure thermal, chemical and electrical exertion during the service life of transformer.

\section{Funding}

This research received no external funding.

\section{Acknowledgments}

The authors express their heartfelt gratefulness to authorities of Siksha 'O' Anusandhan Deemed to be University for the inspiration to pursue this research work. They also acknowledge Prof. M.R. Acharya, Department of physics OUAT for his kind help. 


\section{An Insight on Thermophysical Properties of Binary Mixtures of Hydrocarbons with Spectroscopic Evidence; Essential Components of Transformer Oils}

\section{Conflicts of Interest}

The authors declare no conflict of interest.

\section{References}

1. Ouaar, F.; Negadi, A.; Bahadur, I.; $7 . \quad$ Kasahara, Y.; Suzuki, Y.; Kabasawa, A.; Phadagi,R.;Feddal-Benabed,Negadi, L.; Volumetric, Minami, H.; Matsuzawa, H.; Iwahashi, M.; CH/ $\pi$ acoustic and transport properties of mixtures containing dimethyl sulfoxide and some amines or alkanolamines:

Measurement and correlation. J. Chem. Thermodynamics. 2018, Volume 121, pp.187-198. https://doi.org/10.1016/i.jct.2018.02.018

2. Kashyap, P.; Rani, M.; Gahlyan, S.; Tiwari, D.P.; Maken, S.; Volumetric, acoustic and optical properties of binary mixtures of 2-propanol with nalkanes (C6-C10) from 293.15k to 303.15K. J. Mol. Liq. 2018, Volume 268, pp.303-314.

https://doi.org/10.1016/i.molliq.2018.07.043

3. Prak, D.J.L.; Ye, S.; McLaughlin, M.; Cowart, J.S.; Trulove, P.C.; Density, viscosity, speed of sound, bulk modulus, surface tension and flash point of selected ternary mixtures of $\mathrm{n}$ butylcyclohexane + alinear alkane (n-hexadecane or $\mathrm{n}$-dodecane) + an aromatic compound (toluene, $\mathrm{n}$ butylbenzene, or n-hexylbenzene). J. Chem. Eng. Data. 2017, volume 62, pp. 3452-3472.

\section{https://doi.org/10.1021/acs.jced.7b00466}

Verma, S.; Gahlyan, S.; Rani, M.; Maken, S.; Optical and acoustic properties of binary mixturesof butanol isomers asoxygenates with cyclohexane, benzene and toluene at

308.15K. Korean Chem. Eng. Res. 2018, Volume 56, pp. 663-678.

https://doi.org/10.9713/kcer.2018.56.5.663

4. Jannelli, L.; Pansini, M.; Lopez, A.; Thermodynamic and physical properties of binary mixtures involving nitrobenzene + the first term of aliphatic and aromatic nitrile series. Fluid Phase Equilibr. 1983, Volume 15, pp. 219-229. https://doi.org/10.1016/0378-3812(83)80154-X

5. Domanska, U.; Zawadzki, M.; Phase equilibria of (pyrrole+ benzene and cyclohexane) binary systems. J. Chem. Eng. Data. 2010, Volume 55, pp.5413-5421. https://doi.org/10.1021/je100526j

6. Lal, K.; Tripathi, N.; Dubey, G.P.; Densities, viscosities and refractive indices of binary liquid mixtures of hexane, decane, hexadecane, and squalanewith benzene at 298.15K. J. Chem. Eng. Data. 2000, Volume 45, pp.961-964. https://doi.org/10.1021/je000103x interaction between benzene and hydrocarbons having six carbon atoms in their binary liquid mixtures.J. Oleo Sci. 2010, Volume 59, pp. 21-29. https://doi.org/10.5650/jos.59.21

8. Gonzalez, B.; Gonzalez, E.J.; Dominguez, I.; Dominguez, A.;Excess properties of binary mixtures hexane, heptane, octaneandnonane with benzene, toluene and ethylbenzene at $\mathrm{T}=$ 283.15and 298.15K. Phys. Chem .Liq. 2010, Volume 48, pp. 514-533. https://doi.org/10.1080/00319100903161499

9. Rouabeh, J.; Barki, L.M.; Hammami, A.; Jallouli, I.; Driss, A.; Studies of different types of insulating oils and their mixtures as an alternative to mineral oil for cooling power transformers. Heliyon. 2019, Volume 5, pp.1-19. https://doi.org/10.1016/i.heliyon.2019.e01159

10.Nain, A.K.; Chandra, P.; Pandey, J.D.; Gopal, Swarita.; Densities, refractive indices and excess properties of binary mixtures of 1,4-dioxane with benzene, toluene, o-xylene, m-xylene, $\mathrm{p}$-xylene and mesitylene at temperatures from (288.15 to 318.15)K. J. Chem. Eng. Data. 2008, Volume 53, pp. 2654-2665. https://doi.org/10.1021/je800579j

11. Cominges, B.E.D.; Pineiro, M.M.; Mosteiro, L.; Iglesias, T.P.; Legido, J.L.; Andrade, M.I.P.; Temperature dependence of thermophysical properties of hexane +1 - hexanol. J. Chem. Eng. Data. 2001, Volume 46,pp.1206-1210. https://doi.org/10.1021/ie010039z

12. Malek, N.I.; Ijardar, S.P.; Oswal, S.B.; Volumetric and acoustic properties of binary mixtures of cyclohexane + benzene and +benzaldehyde at (293.15-323.15)K. Thermochim. Acta. 2012, Volume 539, pp. 71-83. https://doi.org/10.1016/j.tca.2012.04.002

13.Zheng, X.; Zhang, Y.; He, M.; Measurement of speed of sound in hexane and heptane at temperatures from (303.15 to 536.15) K and pressures from (1.0 to 8.5)MPa. J. Chem. Eng. Data. 2016, Volume 61, pp. 701-711. https://doi.org/10.1021/je501106d

14. Pradhan, S.; Mishra, S.; A thermodynamic investigation on solute - solvent interactions through volumetric, ultrasonic, dielectric, refractive 


\section{Sanghamitra Pradhan, Manaswini Chhotaray, Sujata Mishra}

ind excess properties of binary mixtures of tri-nbutyl phosphate with dichloro, trichloro and tetrachloromethane at 298.15K. J. Mol. Liq. 2019, Volume 279, pp. 561-570. https://doi.org/10.1016/i.molliq.2019.01.155 15.Devi, R.C.; Mathammal, R.; Kesavasamy, R.; Rohini, V.; Ultrasonic studies of molecular interaction in the ternary liquid mixtures of acrylonitrile + benzene+ $\mathrm{N}$-methyl aniline at different temperatures. Materials Today Proceedings. 2018, Volume 5, pp. 16855-16862. https://doi.org/10.1016/i.matpr.2018.05.111

16. Kumar, S.; Guganathan, L.; Malathi, M.; Mohan, A.; Amalanathan, R.; Dielectric Relaxation studies of Methyl acetate with 2-Alkoxyethanols using Time Domain Reflectometry Technique.International Journal of Scientific Research in Physics and Applied Sciences, 2018, Volume 6, pp.27-40. https://doi.org/10.26438/ijsrpas/v6i5.2740
17. Kolasinska, G.; Goral, M.; Giza, J.; VapourLiquid Equilibria and Excess Gibbs Free Energy in Binary Systems of Acetone with Aliphatic and Aromatic Hydrocarbons at 31315 K. Int. J. Res. Phy. Chem. Chem. Phy. 2017, Volume 263, pp. 151-160. https://doi.org/10.1515/zpch-1982-26317

18. Gahlyan, S.; Verma, S.; Rani, M.; Maken, S.;Viscometric and FTIR studies of molecular interactions in 2-propanol+hydrocarbons mixtures at 298.15 and 308.15 K. Korean J. Chem. Eng. 2018, Volume 35 , pp. 1167. https://doi.org/10.1007/s11814-018-0020-1 